\title{
Grasp Links about Enhancing the Effectiveness of Classroom Education
}

\author{
Weicheng Chen, Yanhui Zhao \\ Bengbu Automobile NCO Academy, Bengbu 233011, China (zhaoyanhui2005@sina.com)
}

\begin{abstract}
The paper puts forward interactive teaching mode. It discusses how to grasp several key links from the formation of rational knowledge, creates a good atmosphere, flexibles implementation guide and does the answering questions and doubts in the interactive classroom education, that provides some useful reference for improving the effectiveness of classroom education.

Keywords - interactive mode, classroom teaching, effectiveness

\section{增强院校课堂教育实效应把握好的几个环节}

\author{
陈伟成 赵艳辉 \\ 蚌埠汽车士官学校, 蚌埠, 安徽, 中国
}

\begin{abstract}
摘 要 论文提出了互动模式教学, 并重点从形成理性认识、营造良好氛围、实施灵活引导、做好答疑解惑等方面论述了互动式 课堂教育应当把握的几个重点环节, 为提高课堂教育实效提供几点有益的参考。

关键词 互动模式, 课堂教育, 实效
\end{abstract}

\section{1. 引言}

院校教学任务转型以来, 随着形势的发展和教育对象 的变化, 课堂教育惯用的传统灌输模式越来越显示出局限 性, 不仅教育者受累, 更造成了作为教育对象的学员消化 不良, 影响了教育效果, 因而必须加以革新。互动模式是 一种强调教学相长的新理念, 在地方素质教育中得到广泛 运用。思想政治教育者应积极借鉴地方成功经验, 尽快将 互动模式纳入到研究视野和能力范围中, 趟开互动式课堂 教育的路子, 重点应把握好以下几个环节。

\section{2. 形成理性认识}

对互动模式, 一些同志存有模糊看法: 有的认为老传 统是传家宝不能丢, 有的觉得学员素质参差不齐搞不出名 堂, 还有的担心有损教育者的权威。所以开展好互动式课 堂教育首先要澄清这些思想上的误区, 教育者要本着事实 求是的精神、为思想政治建设高度负责的态度, 正确地评 价互动模式。

\section{1 拓宽了教育渠道, 壮大了教育力量。}

当前课堂教育效果不尽人意的症结很大程度在于把理
论教育和行政命令混为一体, 把服从观念带到课堂教育中。 这就违背了接受心理的规律, 必然产生事倍功半甚至徒然 无功的结果。而互动模式强调民主、平等、参与, 通过问 题大家摆, 思想大家亮, 方法大家定, 答案大家找, 促进 单向交流向双向交流的转变; 推动静态交流向动态交流的 转变; 帮助学员由被动接受向主动接受转变。使教育渠道 由 “一枝独秀” 变为 “多管齐下”, 教育力量由 “单打独斗” 变为 “联合作战”。

\section{2 促进了学员合理个性发展。}

课堂教育效果的好坏归根到底要看学员的培育和塑造 怎样。传统模式把学员局限于 “埋头记笔记、大声喊口号”, 忽视其主动性的发挥, 长此以往使学员弱化了精神能力, 形成 “依附型” 人格, 导致退伍、转业后在开放、变革的 社会环境中因 “灵感枯萎” 而难有作为。与之相反, 互动 模式认为所有的教育最终都要通过学员的自我教育来完成 并发挥作用, 尊重并注意唤醒他们的主体意识, 鼓励他们 最大限度地发挥自己的聪明才智, 从而有利于培养出多向 度思维和理性思维的个体。 


\section{3. 营造良好氛围}

置身于宽松、友好的氛围中, 学员才易于采取主动、 合作的态度, 知无不言、言无不尽。为此, 要运用各种方 法, 着力营造好氛围。

\section{1 缓解紧张情感。}

知识是客观而无倾向的。但当知识成为人际交流的媒介 时, 它便具有了情感性。知识的交流首先表现为情感的交 流, 愉快的情感交流可以加强官兵对知识的吸收程度。教 育者要善于运用目光、表情、口头语言和肢体语言, 让学 员感受到赞同、欣赏和信任, 以缓解其陌生感、紧张感。

\section{2 淡化等级观念。}

要使以往 “沉默羔羊” 般的学员叫起来, “一潭静水” 似的会场动起来。就必须在 “平等” 两字上下功夫, 着力 帮助学员凸显平等意识: 淡化他们潜意识中对教育者的角 色敬畏和因自身不够成熟而产生的自卑感, 倡导他们勇于 “当仁不让” 和追求 “真理面前人人平等”。努力促使教育 者和学员为活动内容所吸引, 进入 “忘我” 境界。

\section{4. 实施灵活引导}

灵活引导是运用互动模式增强课堂教育实效的关键环 节。要认真分析、预测学员的接受能力和互动水平, 以高 度负责的精神、耐心细致的态度、科学有效的手段全程实 施好引导。

\section{1 紧紧围绕主题。}

互动模式不是目的而是手段。每次教育都有明确的主 题, 运用互动模式正是为了更有效地促进学员对主题的学 习和领会。这就要求教育者把握好主题的 “控制权”, 对学 员自发的零散思想、无关的消极举措及时加以纠正、调整, 保证围绕主题不动摇。具体来讲: 跑题时, 入轨; 变音时, 调频; 走神时, 提醒; 无声时, 启发; 讲完时, 归纳。

\section{2 防止流于形式。}

教育过程中, 在发挥教育者主导作用和尊重学员主体 地位的辨证把握上, 许多教育者常有失偏颇。有的认为提 问就是互动, 有的把互动等同于聊天。前者是一种表面上 民主, 但实际上教育者仍是主宰的方式, 引起的常是学员 “别喊到我” 的祈祷和 “搜肠刮肚” 的紧张。后者则矫枉 过正, 过分强调 “一团和气”, 以致放弃了教育的引领性、 说服性, 其实质是放任自流式的不负责任。以上两种 “形 似神非” 的互动模式, 在组织教育时要注意加以克服。

\section{3 注重交流技巧。}

当缺乏相应的交流技巧时，教育双方即使都有强烈的 交流愿望，也往往造成 “启而不发、问而不答、导而不行” 的盛尬局面。思想政治教育者应运用适当的交流技巧, 使 得他们乐意思考、抢着发言, 获得激情奔涌、创意绽放的 活泼局面。为此, 可以试用以下方法: 抓住热点问题议, 提高兴奋度; 联系实际问题比, 拨动敏感点; 针对模糊观 点评, 加大启发性。

\section{5. 做好答疑解惑}

运用互动模式, 教育者讲的话数量上减少了, 容易使 人产生 “担子轻了, 可以松口气了” 的感觉。其实与这种 感觉恰恰相反, 担子不是轻了而是重了。因为要讲的话质 量要求变高了, 主要表现在要回答好学员各种各样的问题。 要避免 “下不了台” 的䏒塩, 驾驭好互动模式, 必须练就 以下硬功夫：

\section{1 善于以小见大。}

学员获得了话语权后, 敞开心怀吐露的心声多是个人 的所见、所闻、所想, 相对于要灌输的系统理论显得较为 “细小” 和 “低端”。教育者应该在结合上做文章, 善于把 大道理落脚到小现象、结合到具体事, 以便于接受和消化。

\section{2 敢于直面是非。}

当前社会上思想良莠不齐, 事物泥沙俱下。如果教育 者刻意回避、掩饰那些错误的思想言论、事实和社会现象, 学员一旦通过自己的信息途径得知了某些相反的事实, 就 会对宣传教育产生怀疑和不信任。因此教育者应勇敢面对 而不是有意回避社会现实中的尖锐矛盾和问题, 积极帮助 他们全面而辨证地分析、认识问题, 促进社会主流意识和 价值观的内化。

\section{3 长于辩论析理。}

一些歪歪理、灰段子在部队有一定市场, 怎样抵制和 消除这些思想带来的不良影响? 简单制止往往行不通, 思 想的问题还要靠思想手段来解决, 毛泽东同志曾讲: “你不 研究反面的东西, 就驳不倒它” “没有同这些反面的东西做 过斗争, 你那个唯物主义和辩证法是不巩固的”。这就启示 我们, 正确思想的主流地位不是自封的而是通过与之对立 的诸多观念的交锋和斗争博得的。因而教育者要通过认真 组织辩论、深入互相剖析, 使学员 “心服口服” 地接受教 育, 真正做到用科学理论占据学员思想阵地。 


\section{参考文献(References)}

[1] Duan Linlin. Computer multimedia courseware teaching optimization design. China modern education equipment. 2006, (1), P15-19 (Ch).

[2] Li Dongxiang, Wang Yang. Multimedia Courseware Effectiveness Influence of the Teachers Literacy. Journal of Anhui University, 2011, 45(4), P56-57 (Ch).

[3] Zhu Zhiting. Modern education technology into information technology education. Beijing: Higher Education Press, 2011.89-99, Lizhi Zhang, Haozheng Qin. The teacher education practice thinking knowledge. Modern university Education, 2009, (3).
[4] Yigang Lin. Discussion "reflective practice" teacher education. Teacher Education Research, 2008, (6).

[5] Liujing Zhong, Yanhui Wang. Teachers professional development office on Military Academy. Research on university teachers Chinese, 2009, (4).

[6] Youhua Huang. Occupation Education Reform and Innovation. Publishing House of Electronics Industry.2009 years.

[7] Weidong Lu, Yuecai Xu, Xingyin Li. On the Characteristics of Education Officer College Interpretation of. Chinese Military Education, 2011 (6) 56-58.

[8] Zhiting Zhu. Modern Education Technology into Information Technology Education. Beijing: Higher Education Press, 2011. 89-99. 